\title{
Thoracoscopic right upper lobectomy in a patient with bronchial and pulmonary vein anomalies
}

Mingyon Mun, MD, PhD, Hidenori Goto, MD, Yosuke Matsuura, MD, and Masayuki Nakao, MD, Tokyo, Japan

From the Department of Thoracic Surgical Oncology, The Cancer Institute Hospital, Tokyo, Japan.

Disclosure: The authors reported no conflicts of interest.

The Journal policy requires editors and reviewers to disclose conflicts of interest and to decline handling or reviewing manuscripts for which they may have a conflict of interest. The editors and reviewers of this article have no conflicts of interest.

Received for publication July 26, 2020; revisions received July 26, 2020; accepted for publication Aug 10, 2020; available ahead of print Aug 13, 2020.

Address for reprints: Mingyon Mun, MD, PhD, The Cancer Institute Hospital, 3-8-31 Ariake, Koto-ku, Tokyo 135-8550, Japan (E-mail: mingyon.mun@jfcr.or.jp).

JTCVS Techniques 2020;4:316-8

2666-2507

Copyright (C) 2020 The Authors. Published by Elsevier Inc. on behalf of The American Association for Thoracic Surgery. This is an open access article under the CC BY-NC-ND license (http://creativecommons.org/licenses/bync-nd/4.0/).

https://doi.org/10.1016/j.xjtc.2020.08.020

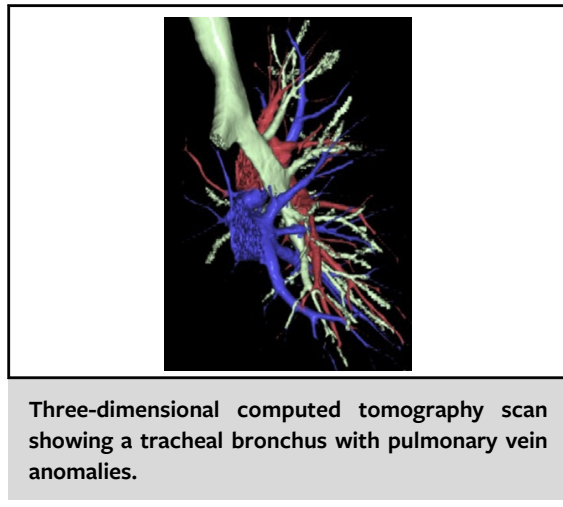

CENTRAL MESSAGE

Tracheal bronchus is sometimes associated with pulmonary vein variation. Preoperative evaluation using 3-dimensional computed tomography is important to foresee anomalies and conduct a safe procedure.

See Commentaries on pages 319 and 321. atively is critical to ensure a safe operational procedure in patients with lung cancer.

\section{CASE DESCRIPTION}

The computed tomography (CT) screening of a 79-yearold woman revealed a pulmonary shadow. Contrastenhanced CT scan disclosed a 32-mm solid ground-glass opacity lesion in the right upper lobe (Figure 1, A). The apical segmental bronchus of the right lung (B1) and the posterior-anterior segmental bronchus of the right lung $(\mathrm{B} 2+3)$ branched independently from the right main bronchus (Figure 1, B). The branches of the PV $(\mathrm{V} 1+3)$ ran between the right main pulmonary artery (PA) and the right main bronchus. An aberrant V2 descended dorsally to the right main bronchus and emptied into the left atrium.

Reconstructed 3-dimensional CT (3D-CT) using simulation software (Volume Analyzer Synapse Vincent; Fujifilm Medical Systems, Tokyo, Japan) revealed the same variation as observed on $\mathrm{CT}$ imaging (Figure 1, $C$ and $D)$. The patient was diagnosed with clinical stage IB (T2aN0M0) lung adenocarcinoma, so we performed right

upper lobectomy with mediastinal lymph node dissection via 4-port video-assisted thoracoscopic surgery (VATS).

The surgical procedure was performed via a $3-$ to $4-\mathrm{cm}$ utility incision on the posterior axillary line in the fifth intercostal space using endoscopic instruments and traditional instruments for sharp dissection. A $15-\mathrm{mm}$ incision was created on the anterior axillary line in the fourth intercostal space for the second assistant. Two 7-mm ports were placed in the center of the third intercostal space for the camera and posteriorly in the fourth intercostal space for the operator's left hand. Two silicone rubber protectors were applied to maintain the 2 wounds in the open position. The superior trunk of the PA and A3 were transected separately using an endostapler. Next, $\mathrm{V} 1+3$ was transected by an endostapler. Two branches of $\mathrm{A} 2 \mathrm{~b}$ were divided after ligation. The $\mathrm{B} 1$ and $\mathrm{B} 2+3$ bronchus was transected separately using an endostapler. The aberrant V2 was divided in conjunction with a posterior fissure (Video 1). The postoperative course was uneventful. 


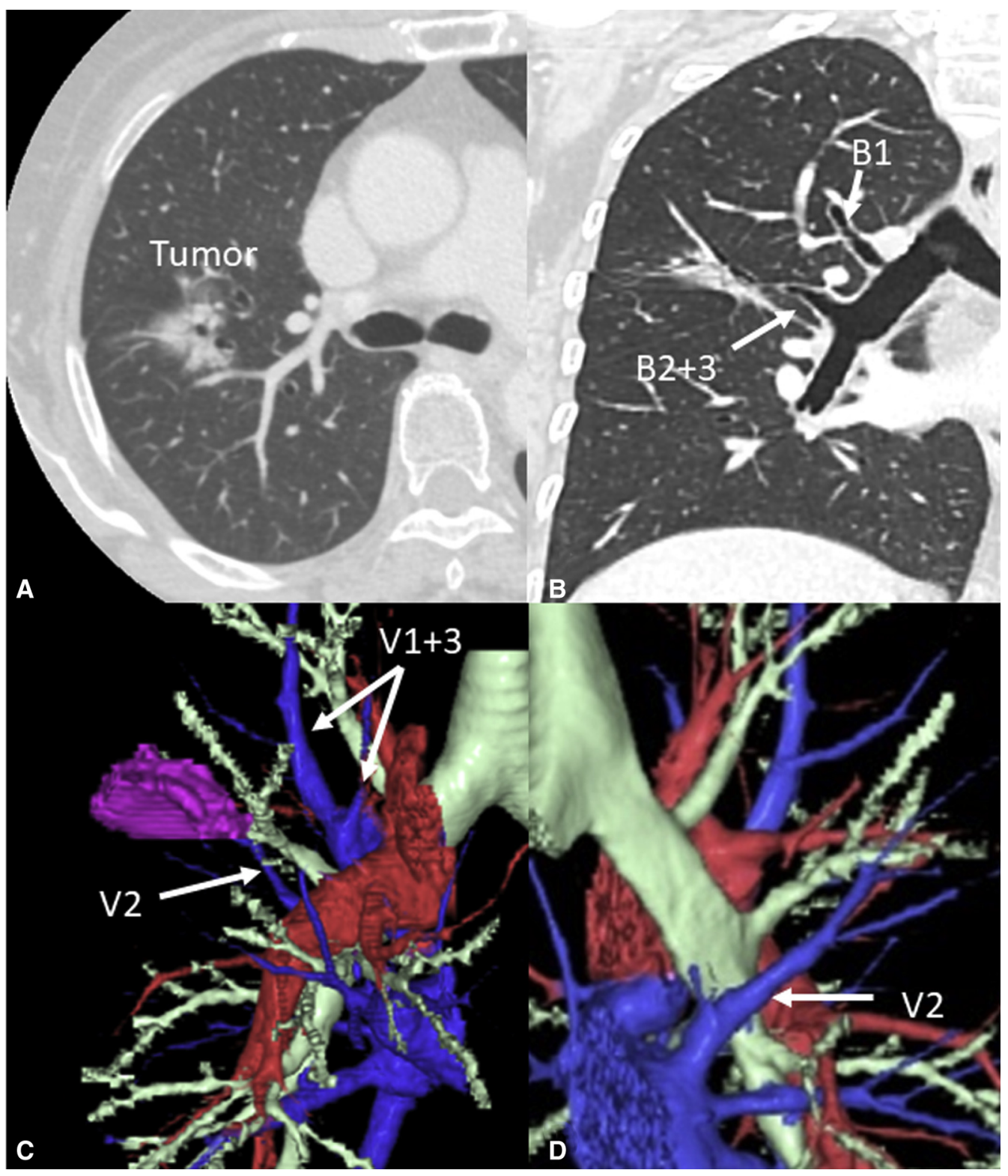

FIGURE 1. Preoperative images. A, Thin-slice computed tomography $(C T)$ showing a partly solid ground-glass opacity in the right upper lobe. (B) The apical segmental bronchus of the right lung (B1) and the posterior-anterior segmental bronchus (B2+3) are branched separately from the right main bronchus. (C) The superior branch of the pulmonary vein $(\mathrm{V} 1+3)$ is running behind the right main pulmonary artery. (D) An aberrant pulmonary vein (V2) is running dorsally, emptying into the left atrium.

The patient provided informed consent for the publication of the study data.

\section{DISCUSSION}

Preoperative evaluation of anatomic anomalies is critical for pulmonary resection. TB is a rare bronchial variation with a reported incidence of $.1 \%$ to $5.0 \% .{ }^{1}$ Furthermore,
TB is sometimes associated with PV variations. Reconstruction 3D-CT is one way to identify the anomalous vessel formation. Tajima et $\mathrm{al}^{2}$ reported a case of TB with a PV anomaly in the right upper lobe, wherein the aberrant V2 descended dorsally to the right main bronchus and emptied into the left atrium. Yurugi et $\mathrm{al}^{3}$ reported a superior PV $(\mathrm{V} 1+2+3)$ running dorsal to the trunk of PA and returning 


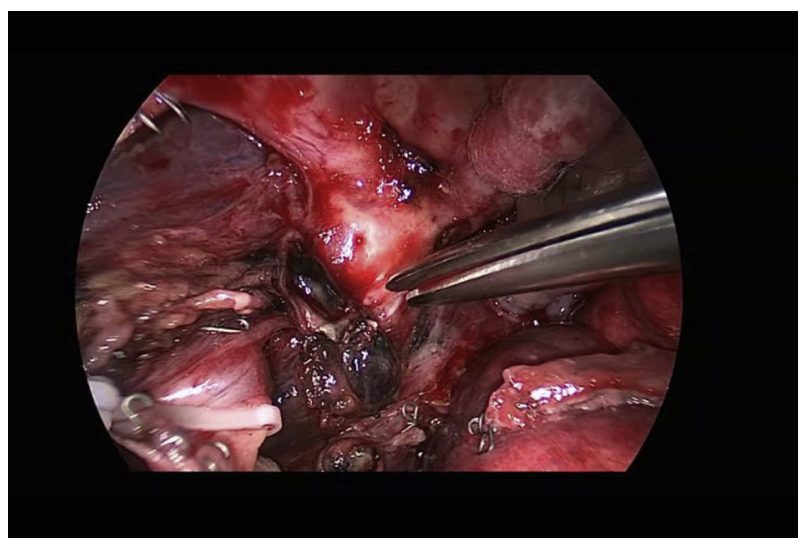

VIDEO 1. In this video, the left side of the monitor is the patient's cranial side. After opening the anterior pleura, at first, the main trunk of the pulmonary artery (PA) was exposed. The superior branch of the pulmonary vein $(\mathrm{V} 1+3)$ was running behind the PA. The superior branch of the PA was divided by an endostapler. The middle lobe lung was partially resected to keep a surgical margin, and the residual minor fissure was divided by an endostapler. After dividing the A3 and A2b, the V1+3 was encircled and divided by an endostapler from the cranial side of the main PA. The apical segmental bronchus of the right lung (B1) was exposed and divided. Then the posterior-anterior segmental bronchus $(\mathrm{B} 2+3)$ was divided in the same manner. The aberrant V2 was divided in conjunction with the posterior fissure by the endostapler. Video available at: https://www.jtcvs.org/ article/S2666-2507(20)30395-3/fulltext.

to the left atrium, which they were not aware of before the operation, and they recommended careful preoperative evaluation for patients with TB. Two more case reports are available on a similar PV anomaly in TB patients, which were detected using 3D-CT preoperatively, and VATS right upper lobectomies were performed safely. ${ }^{4,5}$ In the present study, the anomalous PV was almost identical to that described above (Figure 2, A). In addition, our case had an aberrant V2, which was divided by fissure stapling (Figure 2, B). Although there is no report on the safety related to the synchronous stapling of the segmental PV and the lung parenchyma, we have not encountered any clinical complications after synchronous stapling.

To our knowledge, this is the first report of VATS right upper lobectomy performed in for a patient with both TB and this type of PV anomaly. During VATS, sufficient palpation to the pulmonary vessels is difficult to accomplish. Moreover, the PA vessel wall is more fragile than the PV vessel wall; therefore, confusing the pulmonary vessels may cause massive hemorrhage during dissection by VATS.

In conclusion, several types of PV variants in TB patients have been observed. Therefore, careful preoperative evaluation using 3D-CT imaging is important for a safe VATS.

\section{References}

1. Barat M, Konrad HR. Tracheal bronchus. Am J Otolaryngol. 1987;8:118-22.

2. Tajima K, Uchida N, Sasamoto H, Okada T, Kohri T, Mogi A, et al. Lung adenocarcinoma with anomalous bronchi and pulmonary veins preoperatively identified by computed tomography. Thorac Cancer. 2016;7:599-601.

3. Yurugi Y, Nakamura H, Taniguchi Y, Miwa K, Fujioka S, Haruki T, et al. Case of thoracoscopic right upper lobectomy for lung cancer with tracheal bronchus and a pulmonary vein variation. Asian J Endosc Surg. 2012;5:93-5.

4. Sumitomo R, Fukui T, Otake Y, Huang CL. Video-assisted thoracoscopic lobectomy with an anomalous pulmonary vein. J Thorac Cardiovasc Surg. 2016;152: 1398-9.

5. Ichiki Y, Kakizoe K, Hamatsu T, Suehiro T, Koike M, Tanaka F, et al. A rare anomaly of the right superior pulmonary vein: report of a case. Int J Surg Case Rep. 2017;38:26-8.

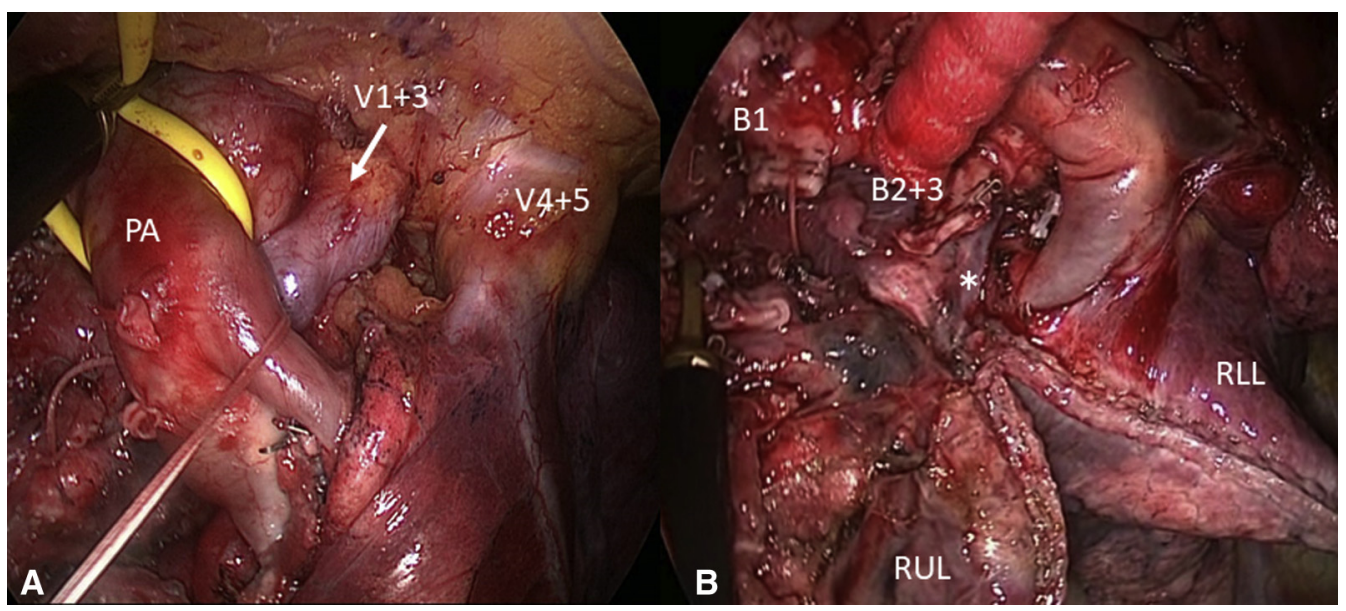

FIGURE 2. Intraoperative thoracoscopic views. The left side of the figure is the cranial side of the patient. (A) The main trunk of the pulmonary artery ( $P A$ ) is taped. The white arrow shows the superior branch of the pulmonary vein $(\mathrm{V} 1+3)$ running behind the PA. (B) The asterisk shows the aberrant V2 running in the superior segment of the lower lobe. The $\mathrm{B} 1$ and $\mathrm{B} 2+3$ have already divided. RUL, Right upper lobe; $R L L$, right lower lobe. 